\title{
A UTILIZAÇÃO DE AGREGADO RECICLADO NA CONFECÇÃO DE CONCRETO ${ }^{1}$
}

\author{
THE USE OF RECYCLED AGGREGATE IN CONCRETE MANUFACTURING
}

\author{
Wagner Fenili de Borba ${ }^{1}$ \\ Gabriela Cassol ${ }^{2}$ \\ Liane da Silva Bueno 3
}

\section{RESUMO}

O objetivo desse estudo foi avaliar o uso dos resíduos de concreto em substituição, parcial ou total, do agregado graúdo natural na confeç̧ão de concreto, a fim de diminuir os custos e evitar o impacto ambiental. Os ensaios laboratoriais foram realizados no laboratório de concreto e argamassa da Universidade Alto Vale do Rio do Peixe (UNIARP) Campus de Caçador/SC. Foram realizados a caraterização dos agregados utilizados, bem como a dosagem do concreto e ensaios no estado fresco e endurecido. O agregado graúdo natural (AGN) apresentou granulometria mais uniforme, enquanto que o agregado graúdo reciclado de concreto (AGRC) apresentou maior heterogeneidade entre as partículas. Em relação ao concreto, a evolução da resistência à compressão foi gradual ao longo dos dias em todos os traços, porém no concreto confeccionado com 100\% AGRC, a resistência a compressão aos sete dias após a confecção já é maior que os demais e aumentou de maneira moderada até os 28 dias de idade, chegando a valores 18,9\% superiores ao concreto padrão. Diante disso, pode se afirmar que o concreto feito a partir de AGRC tem características similares, e até superiores, ao concreto convencional e pode ser usado em substituição aos agregados naturais sem perdas nas características estruturais, diminuindo assim os impactos ambientais causados pela exploração desses recursos.

Palavras-Chave: Agregado graúdo de concreto reciclado, concreto com agregados reciclados, sustentabilidade.

\footnotetext{
${ }^{1}$ Formando do Curso de Engenharia Civil, UNIARP, Caçador-SC, wagnerfenili@hotmail.com

${ }^{2}$ Mestre Engenharia Civil, UNIARP, Caçador-SC, gabriela_cassol@hotmail.com

3 Mestre em Engenharia Civil. Doutora em Engenharia de Produção. UNIARP, Caçador-SC. civil@uniarp.edu.br.
} 


\section{ABSTRACT}

The objective of this study was to evaluate the use of waste concrete in replacement, partial or total, big household natural in the confection of concrete, in order to cut costs and avoid the environmental impact. The laboratory tests were performed at the laboratory of concrete and mortar University Alto Vale do Rio do Peixe (UNIARP) Campus of Caçador/SC. Were performed the characterization of the aggregates used, as well as the concrete dosing and tests in the fresh state and hardened. The big household natural (AGN) presented more uniform particle size, while the big recycled aggregate concrete (AGRC) presented greater heterogeneity between the particles. In relation to the concrete, the development of resistance to compression was gradual over the days in all traits, but in concrete made with $100 \%$ AGRC, resistance to compression to seven days after the bone is already greater than the remaining and dramatically increased moderate until the 28 days of age, reaching values of $18.9 \%$ higher than the standard concrete. Moreover, one can affirm that the concrete made from AGRC has similar characteristics, and even superior to conventional concrete and can be used as a replacement for natural aggregates without losses on structural characteristics, thus reducing the environmental impacts caused by the exploitation of these resources.

Keywords: Aggregate coarse recycled concrete, concrete with recycled aggregates, sustainability.

\section{INTRODUÇÃO}

A sociedade moderna vive em intensa busca ao progresso, construções, inovações tecnológicas, grandes obras, construções magnificas e grandiosas. Pensa-se estarmos seguindo um caminho promissor, no entanto, ao transitar em alguns ambientes, podemos tropeçar em fragmentos, entulhos que são retirados de canteiros de obras, entulhos estes que são despejados, muitas vezes, de maneira desordenada e irregular em ambientes inapropriados, causando grande impacto ambiental. Diante de uma nova preocupação que está a afligir a humanidade, o impacto ambiental e a escassez de recursos naturais, surge a ideia inovadora de reciclagem de materiais oriundos de demolições e resíduos de canteiros de obras, na confecção de concreto (JACOBI e BESEN, 2011).

A preocupação com a destinação correta dos resíduos sólidos provenientes da construção civil, e também a preocupação com o uso de recursos 
não renováveis, faz com que surjam prioridades de uso dentro do sistema. Incluem-se nessas prioridades a redução de resíduos nas fontes geradoras e a redução da disposição final no solo, a maximização do reaproveitamento, da coleta seletiva e da reciclagem. A reutilização de resíduos de construção e demolição (RCD) pode ser uma grande estratégia para minimizar custos e diminuição do impacto ambiental causado pela construção civil.

Atualmente o concreto de cimento Portland é o mais importante material estrutural e de construção civil utilizado no mundo. Segundo Helene e Andrade (2010), mesmo sendo o mais recente dos materiais de construção utilizado para a construção de estruturas, o concreto de cimento Portland pode ser considerado como uma das descobertas mais interessantes da história do desenvolvimento da humanidade.

A demanda mundial por concreto é bastante elevada, visto que o crescimento e a globalização estimula a construção civil. Isto faz com que as indústrias de concreto sejam grandes consumidoras de reservas naturais não renováveis, como as rochas que são fragmentadas e incorporadas aos componentes para dar sustentação e resistência aos agregados. Estima-se que o consumo mundial de concreto seja da ordem de 5,5 bilhões de toneladas por ano, e isso aumenta a demanda por tecnologias que permitam reaproveitar o material e reduzir impacto ambiental (KELM, 2011).

Visto o problema ambiental causado pelo descarte de Resíduo de Construção e Demolição (RCD) no país e, a crescente demanda por matéria prima para confecção de concreto, surge, recentemente no Brasil, a reciclagem desse material, RCD, que antes era desprezado. Estímulos financeiros, como a redução do custo da matéria prima proporcionado pela substituição de material oriundo de fontes não renováveis, por RCD, sem perdas na qualidade final do concreto, abre mercado para reciclagem desses resíduos (MIRANDA et al., 2009).

O reuso e a reciclagem de resíduos têm um potencial de crescimento muito grande, principalmente nos países em desenvolvimento. Neste cenário, a reciclagem de resíduos pela indústria da construção civil vem se consolidando como uma prática importante para a sustentabilidade, seja atenuando o impacto ambiental gerado pelo setor seja reduzindo os custos (LUCAS e BENATTI, 2008).

O uso de RCD na confecção de concreto pode reduzir custos e diminuir o 
impacto ambiental causado pelo descarte incorreto desse material. No entanto há uma preocupação relacionada a qualidade do concreto produzido, devido à grande variabilidade de materiais presentes nos RCD (JACQUES, 2013).

Neste sentido, propõe-se neste artigo, apresentar a confecção de concreto a partir do agregado reciclado de concreto, avaliando-se suas propriedades físicas e mecânicas, além da viabilidade econômica, em comparação ao concreto convencional, a fim de diminuir os custos e evitar o impacto ambiental provocado pelo descarte inadequado desse material.

\section{MATERIAIS E MÉTODOS}

Os ensaios laboratoriais foram realizados no laboratório de Materiais e Solos da Universidade Alto Vale do Rio do Peixe (UNIARP), campus Caçador. Onde, foram confeccionados corpos de prova com uso de agregado graúdo reciclado de concreto em substituição parcial ou total ao agregado graúdo natural, e comparados a corpos de prova confeccionados apenas com agregado graúdo natural. Bem como, realizou-se os ensaios para caracterização dos materiais, e a resistência à compressão dos corpos de prova produzidos.

Com o estudo da granulometria dos agregados utilizados, foram obtidos os percentuais de retenção acumulada dos agregados em várias peneiras, conforme observa-se na Tabela 1 . Onde o agregado miúdo apresentou baixa porcentagem de impureza, no entanto os agregados graúdos mostraram certa distinção entre os seus componentes.

Tabela 1: Porcentagem retida acumulada de material nas peneiras de diferentes granulometrias, para os diferentes agregados utilizados na fabricação do concreto.

\begin{tabular}{|c|c|c|c|c|}
\hline \multirow{2}{*}{$\Phi$ peneira $(\mathrm{mm})$} & AM & \multirow{2}{*}{$\Phi$ peneira $(\mathrm{mm})$} & AGN & AGRC \\
\hline & $\%$ retida acumulada & & \multicolumn{2}{|c|}{$\%$ retida acumulada } \\
\hline$<0.15$ & 100.0 & 4.75 & 100.0 & 100.0 \\
\hline 0.15 & 91.2 & 9.5 & 100.0 & 94.1 \\
\hline 0.3 & 69.4 & 19 & 97.8 & 63.7 \\
\hline 0.6 & 14.3 & 25 & 1.3 & 12.5 \\
\hline 1.18 & 1.9 & 37.5 & 0.0 & 1.1 \\
\hline 2 & 0.8 & 50 & 0.0 & 0.0 \\
\hline 4.75 & 0.3 & & & \\
\hline
\end{tabular}


$9.5 \quad 0.0$

Fonte: Fenili e Cassol (2016)

O agregado miúdo foi padrão para todos os traços de concreto confeccionados, e mostrou-se com alta pureza, visto que apenas $2,1 \%$ de suas partículas ficaram retidas entre as peneiras de $1,18 \mathrm{~mm}, 2 \mathrm{~mm}$ e $4,75 \mathrm{~mm}$. A granulometria dos agregados graúdos mostrou certa heterogeneidade entre os matérias, onde os agregados de origem natural apresentaram a maioria das suas partículas com diâmetro inferior aos $25 \mathrm{~mm}$ e ausência de partículas com diâmetro inferior a 9,5mm, enquanto que nos agregados de concreto reciclado foi observado presença de materiais de diâmetro inferior a 9,5mm e também presença de partículas grandes, superiores a $37 \mathrm{~mm}$.

No volume da massa unitária dos agregados, a massa unitária do agregado graúdo natural (AGN) foi de $1,575 \mathrm{~g} / \mathrm{m}^{3}$ e do agregado graúdo reciclado de concreto (AGRC) foi $1,318 \mathrm{~g} / \mathrm{m}^{3}$.

Ao avaliar a quantidade de material fino aderido ao agregado graúdo, realizado através da NBR NM 46 (ABNT, 2003), observou-se que 1,29\% do agregado graúdo natural (AGN) passa pela peneira de $75 \mu \mathrm{m}$ e 2,20\% no agregado graúdo reciclado de concreto (AGRC). Valores estes que podem ser explicados pela presença de resíduos de argamassa presente junto às partículas de AGRC.

Em relação ao estudo de dosagem, a partir do valor da Resistência Característica do Concreto à Compressão - Fcj e dos resultados dos ensaios de caracterização dos materiais, foram calculados os traços com agregado graúdo natural (100\% AGN - Padrão), com 50\% de substituição de agregado natural por reciclado ( $50 \%$ AGRC), e com $100 \%$ de substituição de agregado natural por reciclado (100\% AGRC), sendo realizado à substituição em massa do agregado natural em relação ao agregado reciclado. Depois de calculada a quantidade de material necessária para a fabricação de cada traço (Tabela 2), o mesmo foi pesado e separado por traço.

Tabela 2: Dosagem dos componentes do concreto elaborado.

\begin{tabular}{lllllll}
\hline \multirow{2}{*}{ Traços } & Agua & Cimento & Areia & AGN & AGRC & Aditivo* \\
\cline { 2 - 7 } & (L) & & \multicolumn{3}{c}{ (g) } \\
\hline 100\% AGN (Padrão) & 4,08 & 6.66 & 13.40 & 19.90 & --- & -- \\
$50 \%$ AGRC & 3,87 & 6.66 & 13.40 & 9.95 & 9.95 & 60 \\
\hline
\end{tabular}




\begin{tabular}{lllllll}
\hline $100 \%$ AGRC & 4,0 & 6.66 & 13.40 & --- & 19.90 & 60 \\
\hline
\end{tabular}

*MIRA RT Polifuncional.

Além disso, a determinação da consistência pelo abatimento do tronco de cone, NBR NM 67 (ABNT, 1998), também conhecido como slump test, na qual se

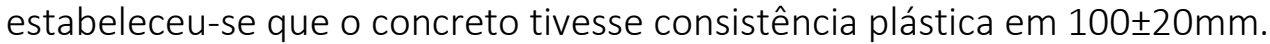

\section{RESULTADOS E DISCUSSÕES}

Ao serem submetidos ao teste de resistência a compressão em prensa hidráulica, os corpos de prova (CP) mostraram comportamento bastante distintos. Os maiores níveis de resistência foram os apresentados no traço $100 \%$ de agregado reciclado, ou seja, com $100 \%$ de agregado graúdo reciclado, conforme explicita a Figura 1. Esta observação também foi relatada por Jacques (2013), que verificou que o concreto confeccionado com agregados $100 \%$ reciclados teve maior resistência a compressão do que o concreto convencional com $100 \%$ de agregado graúdo natural. Uma possível explicação para esse resultado, é o efeito da hidratação avançada dos compostos cimentícios presentes no AGRC (JAQUES, 2013). Já o traço com $50 \%$ de agregado reciclado expressou resistência a compressão similar ao concreto convencional quando avaliado na idade dos 28 dias. 
Gráfico 1: Resistência (MPa) x Idade (dias)

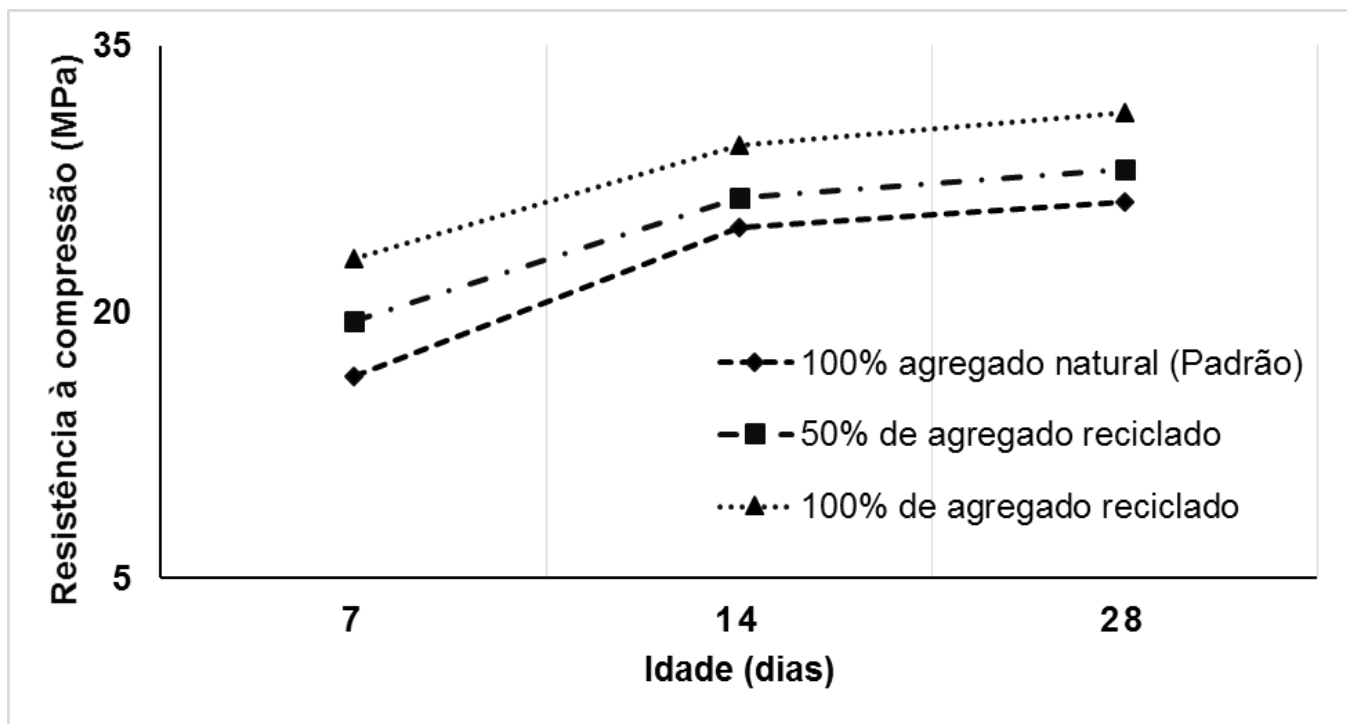

Fonte: Fenili e Cassol (2016)

Ao observar o comportamento da evolução da resistência do concreto ao longo dos dias, conforme mostra a tabela 3, percebemos um aumento gradual nos três traços analisados. No entanto, se percebe que o traço com $100 \%$ de agregado reciclado já tem a maior resistência a compressão na idade de 7 dias que tende a aumentar de maneira moderada até os 28 dias de idade, chegando a valores 18,9\% superiores ao concreto padrão. O que atrai a atenção é o comportamento de evolução da resistência do traço padrão que aumentou em $51 \%$ do sétimo ao decimo quarto dia. Enquanto que o traço $50 \%$ de agregado graúdo reciclado atingiu valores de resistência similares ao padrão, porem em menor gradiente.

Tabela 3: Resultado da Resistência à Compressão (MPa) e Evolução das Resistências (\%).

\begin{tabular}{|c|c|c|c|c|c|c|}
\hline \multirow{3}{*}{ Traços } & \multicolumn{3}{|c|}{$\begin{array}{l}\text { Resistência a compressão } \\
\text { (Mpa) }\end{array}$} & \multicolumn{3}{|c|}{$\begin{array}{c}\text { Evolução das Resistências } \\
(\%)\end{array}$} \\
\hline & 7 & 14 & 28 & \multirow{2}{*}{7 ao 14} & \multirow{2}{*}{14 ao 28} & \multirow{2}{*}{7 ao 28} \\
\hline & & dias & & & & \\
\hline $\begin{array}{l}\text { 100\% agregado natural } \\
\text { (Padrão) }\end{array}$ & 16,39 & 24,76 & 26,23 & 51,07 & 5,94 & 60,04 \\
\hline $50 \%$ de agregado reciclado & 19,46 & 26,47 & 28,07 & 36,02 & 6,04 & 44,24 \\
\hline $100 \%$ de agregado reciclado & 22,97 & 29,4 & 31,2 & 27,99 & 6,12 & 35,83 \\
\hline
\end{tabular}

Fonte: Fenili e Cassol (2016) 


\section{CONSIDERAÇÕES FINAIS}

O uso de agregados graúdos de concreto reciclado na confecção de concreto, não causa nenhum comprometimento as características de resistência desse material. Podendo assim, ser substituído sem perdas de qualidade.

O concreto feito a partir de agregados reciclados tem características similares, e até superiores ao concreto convencional e, pode ser usado em substituição aos agregados naturais sem perdas nas características estruturais, além de diminuir os impactos ambientais causados pela exploração desses recursos.

Com a utilização de agregados reciclados, pode-se conseguir significativa redução dos custos finais das obras e melhor uso desses materiais, o que indica-se como temas a serem estudados em futuros trabalhos.

\section{REFERÊNCIAS}

ASSOCIAÇÃO BRASILEIRA DE NORMAS TÉCNICAS. NBR NM 46: Agregados Determinação do material fino que passa através da peneira 75 um, por lavagem. Rio de Janeiro, 2003.

ASSOCIAÇÃO BRASILEIRA DE NORMAS TÉCNICAS. NBR NM 67: Concreto Determinação da consistência pelo abatimento do tronco de cone. Rio de Janeiro, 1998.

FENILI, Wagner de Borba; CASSOL, Gabriela. Confeç̧ão de Concreto com Utilização de Agregado Reciclado. Congresso Técnico Científico da Engenharia e da Agronomia (CONTECC'2016), Foz do Iguaçu, 2016.

HELENE, P.; ANDRADE, T. Concreto de Cimento Portland In: Materiais de Construção Civil e Princípios de Ciência e Engenharia de Materiais. IBRACON, 2010, p.905-944.

JACOBI, P. R.; BESEN, G. R. Gestão de resíduos sólidos em São Paulo: desafios da sustentabilidade. Estudos avançados, São Paulo, v. 25, n. 71, p. 135-158, Abril. 2011.

JACQUES, J. R. Estudo da viabilidade técnica da utilização de concreto reciclado como agregado graúdo em concreto de cimento Portland. 63f. Trabalho de 
Conclusão de Curso (Graduação em Engenharia Civil). Universidade Regional do Noroeste do Estado do Rio Grande do Sul. Ijuí, 2013.

KELM, T. A. Análise da Resistência e Microestrutura em Concretos Com Substituição Parcial de Cimento Por Microssílica da Cinza de Casca de Arroz. $54 f$. Trabalho de Conclusão de Curso (Graduação em Engenharia Civil). Universidade Regional do Noroeste do Estado do Rio Grande do Sul, 2011.

LUCAS, D.; BENATTI, C. T. Utilização de resíduos industriais para a produção de artefatos cimentícios e argilosos empregados na construção civil. Revista em Agronegócios e Meio Ambiente, v. 1, n.3, p. 405-418, 2008.

MIRANDA, L. F. R.; ÂNGULO, S. C.; CARELI, É. D. A reciclagem de resíduos de construção e demolição no Brasil: 1986-2008. Ambiente Construído, Porto Alegre, v. 9, n. 1, p. 57-71, 2009. 